\title{
Habitat fragmentation, patch size, and the recruitment and abundance of kelp forest fishes
}

\author{
Andres A. Deza ${ }^{1,2, *}$, Todd W. Anderson ${ }^{1}$ \\ ${ }^{1}$ Department of Biology and Coastal \& Marine Institute, San Diego State University, San Diego, California 92182-4614, USA \\ ${ }^{2}$ Present address: University of California Santa Barbara - SONGS Mitigation Project, 2270 Camino Vida Roble Suite D, \\ Carlsbad, California 92011, USA
}

\begin{abstract}
Studies of habitat fragmentation in marine ecosystems are few, despite a high potential for disturbance and the fragmentation of macrophytes that constitute important habitats. In this study, we investigated the relative importance of habitat fragmentation and loss on the recruitment and abundance of fishes associated with giant kelp Macrocystis pyrifera forests. We experimentally fragmented naturally occurring kelp forests at 3 sites along Santa Catalina Island, California, USA, into areas of 100 to $1600 \mathrm{~m}^{2}$. We also explored the relationship between kelp patch size and recruitment of fishes at smaller spatial scales by constructing kelp plots that were consistent in density but varied in area. The numerical and biomass densities of recruit, older juvenile, and adult fishes across fragment areas differed among species, resulting in linear, exponential, or asymptotic increases in numerical and biomass abundances with fragment size. Overall, fishes exhibited mostly linear relationships between abundance and fragment area, suggesting that kelp-associated fishes are more affected by habitat loss than by fragmentation. When incorporating kelp forests of larger area, however, formerly linear functions became non-linear, indicating that habitat fragmentation may become more important at larger spatial scales. At the scale of small kelp patches, the densities of Paralabrax clathratus and Oxyjulis californica were unrelated to patch size, and recruitment occurred in the smallest patches and was highly variable for both species. These results may provide resource managers with important information on the relative effects of habitat loss and fragmentation in the conservation and management of coastal fishes.
\end{abstract}

KEY WORDS: Disturbance $\cdot$ Habitat fragmentation $\cdot$ Patch size $\cdot$ Giant kelp $\cdot$ Macrocystis pyrifera Reef fishes · Recruitment

\section{INTRODUCTION}

A long-standing goal of ecology has been to understand the relationships between organisms and the habitats in which they reside (Bell et al. 1991). More recently, there has been a focus on the effects of habitat loss and fragmentation on biodiversity (Fahrig 2003) and the distribution and abundance of species (Wiegand et al. 2005). Relationships between an organism and the size of its habitat certainly vary among taxa (birds: Conner \& Rudolph 1991; lizards: Hokit \& Branch 2003; beetles: Crist \& Ahern 1999).
However, studies that have investigated the effects of disturbance on habitats have focused primarily on the loss of habitat and not on fragmentation explicitly (but see Fahrig 2003 and Johnson \& Heck 2006).

Habitat fragmentation has been described as a landscape process involving habitat loss, reduced patch size, and an increase in the distance among patches of remaining habitat as a result of both natural or anthropogenic disturbances (Andrén 1994). Such disturbances vary in magnitude and fragment habitat differentially, which, in turn, produces species-specific responses depending on an organism's ecological requirements. In 
many studies, however, the effects of habitat loss have not been sufficiently decoupled from habitat fragmentation and are often examined at small spatial scales, both of which may result in equivocal interpretation of the results (Fahrig 2003).

Studies of fragmentation in marine environments are relatively few and for the most part have focused on seagrass habitats (Eggleston et al. 1998, Hovel \& Lipcius 2001, 2002; but see Caley et al. 2001). These studies suggest that the density and survival of invertebrates vary with respect to patch size and habitat structural complexity. For example, shrimp are more abundant in small patches of seagrass because of the importance of a large perimeter-to-area ratio for feeding (Eggleston et al. 1998), whereas the survival of juvenile blue crabs is greater in more structurally complex habitat as a refuge from predation, regardless of patch size (Hovel \& Lipcius 2002). The effects of patch size on local invertebrate communities also vary. Although a greater number of invertebrate taxa and differences in the composition of assemblages occur in larger versus smaller seagrass habitats (Bowden et al. 2001), the diversity of invertebrates may be affected more by the presence of seagrass than by its patch size (Hirst \& Attrill 2008). In contrast to invertebrates, few studies have focused on the consequences of habitat fragmentation and patch size for marine fishes in seagrass ecosystems (Fernandez et al. 2005, Jelbart et al. 2006, Johnson \& Heck 2006).

On temperate rocky reefs, considerable habitat is provided by macroalgae in the form of kelps (e.g. Dayton 1985, Foster \& Schiel 1985). The density and abundance of many temperate reef fishes are positively related to the presence and abundance of kelps (Choat \& Ayling 1987, Ebeling \& Hixon 1991), particularly giant kelp Macrocystis pyrifera in California, USA (reviewed by Stephens et al. 2006), and elsewhere (Moreno \& Jara 1984). Recruitment (input of young fish) of reef fishes in kelp habitats is strongly influenced by the structural complexity of kelps (Carr 1991, 1994, Anderson 1994) as a refuge from predation (Ebeling \& Laur 1985, Anderson 2001, Johnson 2006). Both observational (Larson \& DeMartini 1984, Bodkin 1986, DeMartini \& Roberts 1990, Holbrook et al. 1990) and experimental (Bodkin 1988, Carr 1991, 1994, O'Connor \& Anderson 2010) studies have shown that reductions in the density of giant kelp negatively affect the abundance of recruits and older reef fishes. Consequently, disturbances that result in the loss and fragmentation of kelp forests have the potential to cause substantial variation in recruitment and the abundance of rocky reef fishes.

Importantly, disturbances to giant kelp forests that result in the thinning, fragmentation, or absence of kelp are common. Winter storms can reduce the densities of giant kelp for several kilometers of coastline (Dayton et al. 1992), and more severe events such as the El Niño Southern Oscillation (ENSO) are capable of completely removing kelp at a much larger spatial scale (Edwards \& Hernandez-Carmona 2005, Edwards \& Estes 2006). Kelp grazing by sea urchins may lead to severe deforestation and fragmentation of nearshore kelp forests (Cowen et al. 1982, Ebeling et al. 1985, Springer et al. 2003). Anthropogenic disturbance such as sedimentation can reduce the density of kelp by decreasing the amount of light available for photosynthesis (Tegner et al. 1995) or covering young propagules, preventing their growth and development (Devinny \& Volse 1978). Given the many disturbances capable of fragmenting kelp forests and the importance of kelp structural complexity to recruitment and the abundance of fishes, fragmentation may have adverse effects on reef fish populations.

In this study we investigated (1) the effects of fragmentation of giant kelp forests on the density and abundance of rocky reef fishes, and (2) the relationship between kelp patch size and recruitment of kelp-associated fishes at a smaller spatial scale. For the first objective, it is important to note whether and how the densities and extrapolated abundances of fishes may change across a gradient of kelp fragmentation to provide insight on the relative importance of habitat loss and fragmentation within kelp forests (Fig. 1). For example, a species that exhibits similar numerical or biomass densities across sizes of fragments should exhibit a simple positive linear relationship between fish abundance and fragment area, and because of this additive relationship, the amount and not the size of the habitat is most important, indicating that habitat loss has a much greater impact on kelp forest fishes than fragmentation. Alternatively, a species that increases in density with increasing fragment size should reveal a positive, exponential increase in the abundance of fishes because of the combination of increasing density and habitat area. In this case, habitat fragmentation should be more important than habitat loss because the abundance of fishes declines substantially with smaller differences in the degree of fragmentation. By contrast, if the density of fish is negatively related to fragment size, a positive but saturating asymptotic function in fish abundance would occur with increasing fragment size. Here, both habitat loss and fragmentation may vary in their influence on kelp forest fishes depending upon the amount of loss and the resulting distribution in size of fragments. Consequently, the frequency and strength of these relationships may have implications for the management of coastal fishes in rocky reef habitats. 


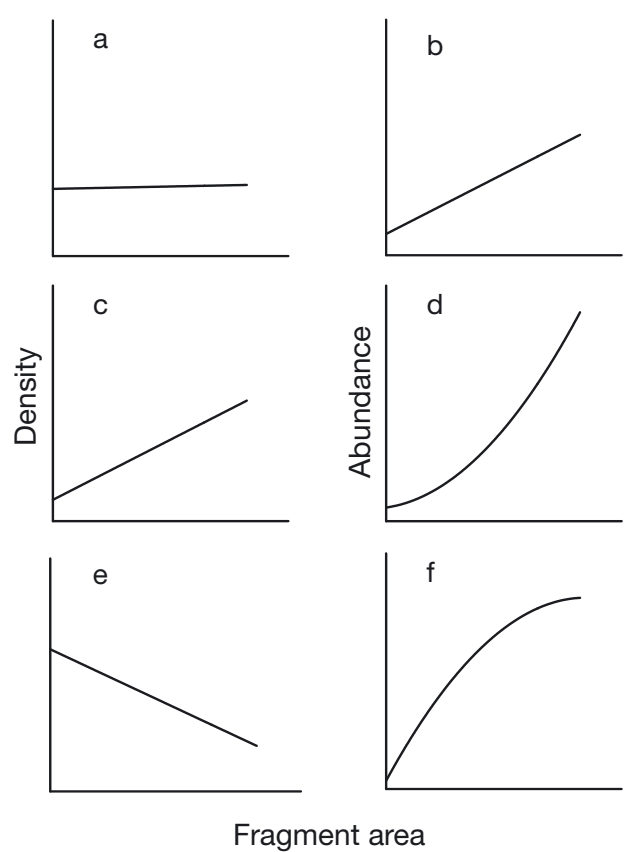

Fig. 1. Predicted relationships between the density and abundance of fishes as a result of habitat loss and fragmentation. $(a, b)$ If density does not differ with fragment area, an additive relationship between abundance and fragment area is the result, indicating that habitat loss is more important than fragmentation. (c,d) If density increases with fragment area, an exponential relationship between abundance and fragment area is realized, indicating that habitat fragmentation is more important than loss. (e,f) If density decreases with fragment area, a saturating, asymptotic function between abundance and fragment area occurs, in which the relative importance of habitat fragmentation and loss depends upon the shape of the curve relative to fragment area

\section{MATERIALS AND METHODS}

Study system. This study was conducted on the leeward side of Santa Catalina Island, near the Wrigley Marine Science Center $\left(33^{\circ} 27^{\prime} \mathrm{N}, 118^{\circ} 29^{\prime} \mathrm{W}\right)$. Rocky reefs along the coastline of the island generally slope steeply with depth, and forests of giant kelp occupy a relatively narrow but consistent width $(\sim 20 \mathrm{~m})$ perpendicular to the shoreline. In addition, the topography of the islands reduces the distribution of other large understory stipitate kelp, which occur in highest abundance in very shallow depths. This configuration of kelp provided an exceptional opportunity to experimentally test the effects of habitat fragmentation in giant kelp forests, because the width of kelp forests, which may alter current flow and velocity (Jackson 1997) and thus the settlement and the distribution of fishes in our study area, is not confounded with fragment size. Three sites spanning a distance of $13 \mathrm{~km}$ were selected in which kelp forests were sufficient in length and similar in configuration for manipulations of habitat fragmentation to be performed (Fig. 2a).
Habitat fragmentation and fish abundance: a mesoscale experiment. Experimental design: In March and June 2005, a series of fragments of kelp forest $(100,200$, $400,600,1000$, and $1600 \mathrm{~m}^{2}$ ) were created at each of the 3 study sites in a randomized block design (Fig. 2b). To establish treatments, meter tapes were laid for $300 \mathrm{~m}$ parallel to shore at the deepest edge of the kelp forest, and flagging tape was used to mark the placement of each fragment. The dimensions of each fragment, which correspond to the area of each treatment listed above were $\sim 20 \mathrm{~m}$ wide and $5,10,20,30$, 50 , and $80 \mathrm{~m}$ long, respectively. To maintain discrete treatments and reduce the potential movement of postsettlement recruit fishes among fragments, a distance of $15 \mathrm{~m}$ between adjacent fragments was cleared of all giant kelp and understory stipitate kelps from the outer to the inner edge of the kelp forest (Fig. 2b). Thus, habitat loss between fragments and among sites was held constant to explicitly examine the effects of habitat fragmentation on kelp forest fishes. Giant kelp was removed by severing individuals just above the holdfast and before the primary dichotomy of stipe bifurcation. All kelps that appeared in clearings between fragments after the initial clearing in 2005 were removed before surveys of fishes were initiated in 2006.

To ensure that the effects of fragmentation were not confounded by differences in the density of giant kelp, estimates of density were determined along transects within fragments at each site for each year in which habitat fragmentation was studied (2005 and 2006). Within each fragment, 2 to 6 random transects $(2 \mathrm{~m}$ width $\times 20 \mathrm{~m}$ length, or $40 \mathrm{~m}^{2}$ ) were surveyed to determine the density of adult kelp (individuals with at least 4 fronds and $>1 \mathrm{~m}$ in height); 2 and 6 transects were established in the $100 \mathrm{~m}^{2}$ and $1600 \mathrm{~m}^{2}$ fragments respectively, and 4 transects were surveyed in all other fragments (Table 1a). A different number of transects was used for each fragment at a given site to obtain more precise estimates of kelp density (Table $1 \mathrm{~b}$ ). For statistical analyses, all densities obtained from belt transects were averaged into a single data point per fragment (see analyses section). All transects were surveyed perpendicular to shore from the outer to the inner edge of each kelp fragment.

This experiment was planned for $3 \mathrm{yr}$, but 2 sites were compromised in 2007 due to a natural cliff collapse and underwater rock slide in the nearshore environment at Arrow Point and Empire Landing, respectively. Therefore, we investigated whether relationships between the density and abundance of fishes and the area of larger kelp forests were consistent with the results from experimental habitat fragmentation. We conducted single surveys of recruit and older fishes in August 2007 at the remaining intact experimental site (Quarry, surveyed in the same manner as in 2005 and 2006) and at 


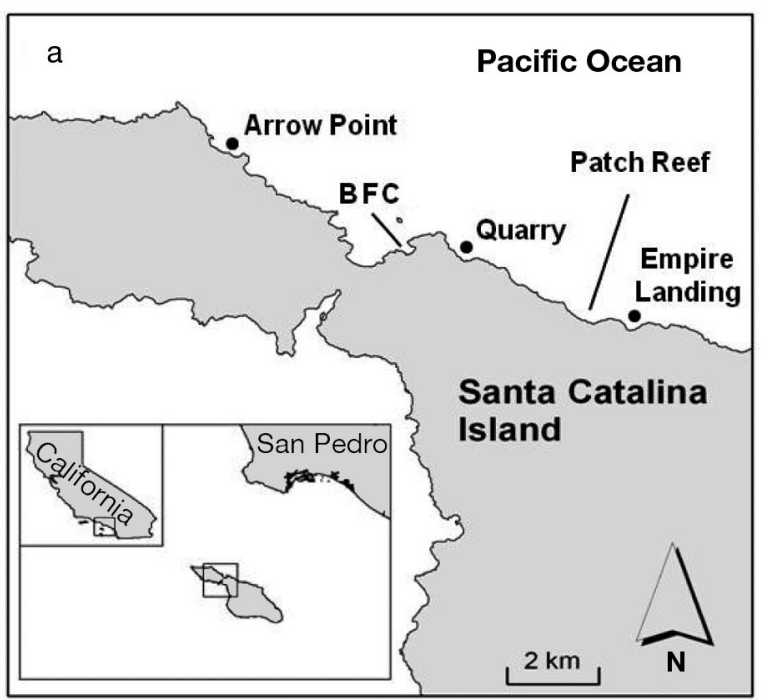

Fig. 2. (a) Study sites at Santa Catalina Island, California. Three sites were used for meso-scale experimental habitat fragmentation in kelp forests: Arrow Point, Quarry, and Empire Landing. Two sites were used for the small-scale patch size experiment: Big Fishermen Cove (BFC) and Patch Reef. (b) Experimental design of habitat fragmentation at each of 3 sites at Santa Catalina Island in 2005. Kelp was cleared in $15 \mathrm{~m}$ sections to create kelp forest fragments of $\sim 20 \mathrm{~m}$ width by $5,10,20,30,50$, and $80 \mathrm{~m}$ length alongshore, representing areas from $100 \mathrm{~m}^{2}$ to $1600 \mathrm{~m}^{2}$
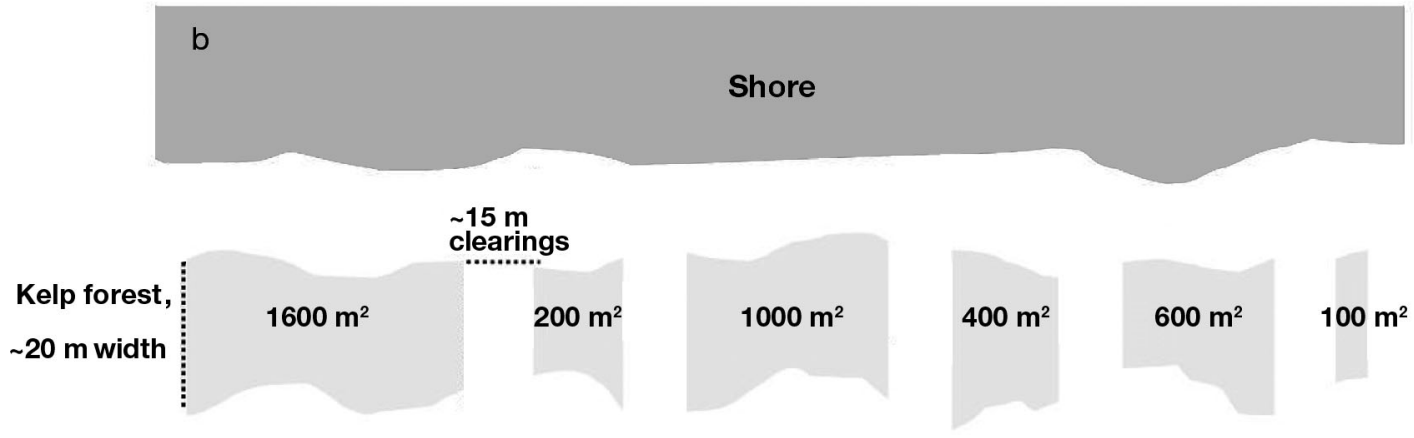

Table 1. (a) Belt transect surveys conducted in meso-scale experiments to assess the effects of habitat fragmentation and loss on kelp forest fishes in 2005 to 2006. (b) Number of replicates and patches used for each treatment in both meso- and small-scale experiments, respectively

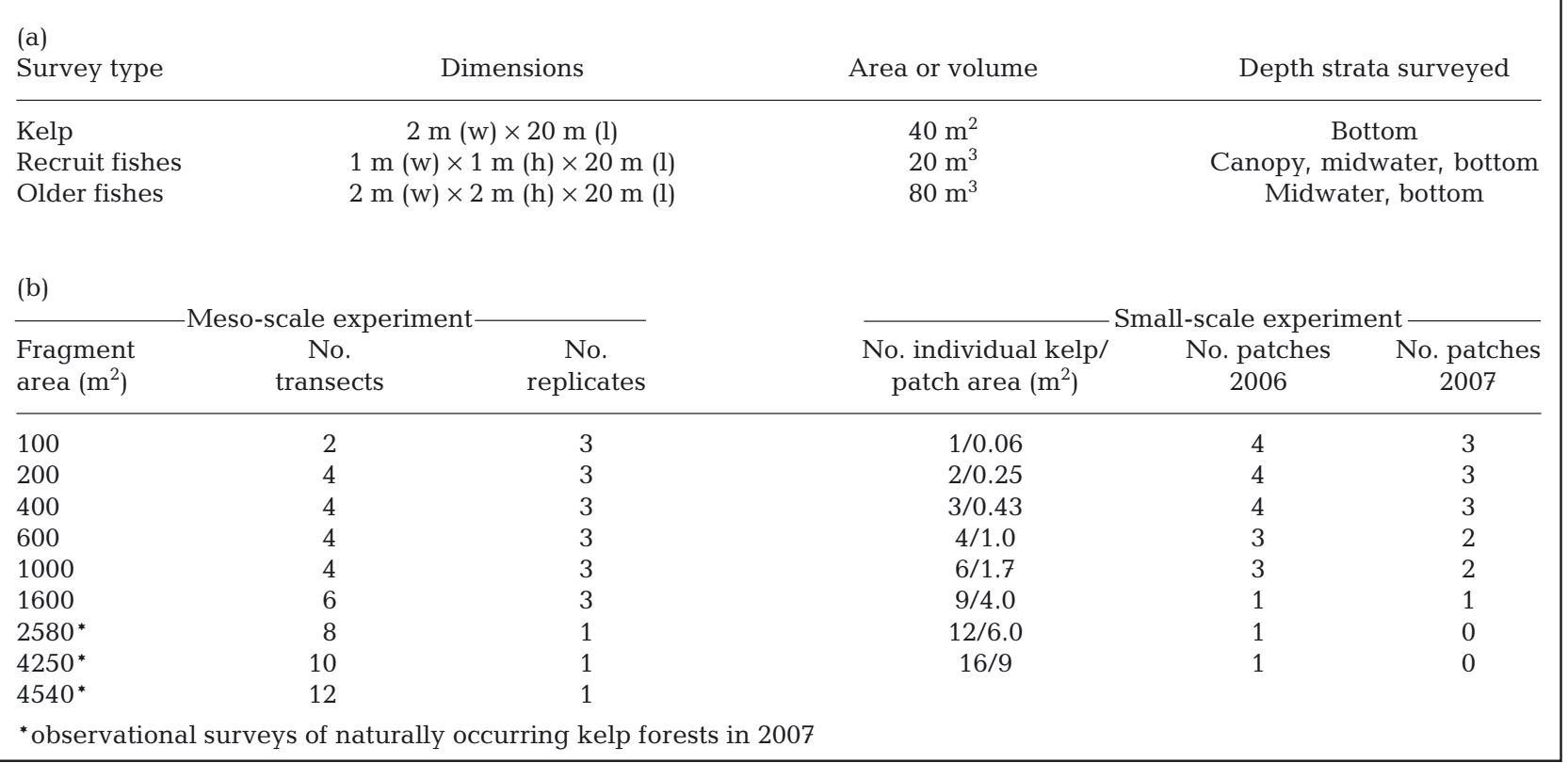


3 naturally occurring kelp forests that were similar in configuration to the manipulated forests used to explore habitat fragmentation. The areas of the natural kelp forests surveyed were $2580 \mathrm{~m}^{2}, 4250 \mathrm{~m}^{2}$, and $4540 \mathrm{~m}^{2}$, measured by extending a transect tape parallel to shore from the beginning to the end of the forest and multiplying the value obtained by the average width of the kelp forest $(20 \mathrm{~m})$. Surveys of fishes were conducted by establishing 8 to 12 transects (depending on the size of the kelp forest) of the same orientation and dimensions used in surveys of older life stage and recruit fishes (see below) in the experiment on habitat fragmentation (Table 1b).

Surveys of recruit and older fishes: Within each fragment, belt transects were surveyed for recruit fishes (young fish which recently settled from the water column to kelp, up to 4 mo old and $\sim 2$ to $8 \mathrm{~cm}$ total length, TL) and for older life stages (juvenile and adult fishes). Two to 6 randomly positioned transects were used per fragment, depending upon fragment area (see 'Experimental design'). More transects were established in larger fragments to obtain more precise estimates of fish density within our largest fragments. Conversely, fewer transects were used in smaller fragments because there was less habitat to survey and only 2 transects fit within the area of the smallest fragments (Table 1b). Transects were followed from the deeper outer edge of the kelp forest (maximum of $15 \mathrm{~m}$ depth) perpendicular to and toward the shore to survey the densities of fishes across depths. Surveys of recruit fishes were conducted in July, August, and October 2005, in June, July, and August 2006, and in 2007 at Quarry. To quantify recruit fishes at each transect position, we sampled fishes in 3 depth strata: kelp canopy (0-2.5 m depth), midwater (midway between the canopy and seafloor; 2.5-7.5 m depth), and bottom (7.5-15 m depth). We used $1 \mathrm{~m}$ wide $\times 1 \mathrm{~m}$ high $\times \sim 20 \mathrm{~m}$ long $\left(20 \mathrm{~m}^{3}\right)$ transects, with transect length depending on the estimated width of the kelp fragment on a transect. An observer would first swim slowly in the kelp canopy towards and perpendicular to shore, recording all species and sizes (TL, cm) of recruits. Upon reaching the inner edge of the kelp forest, the observer would descend to midwater and swim offshore while again recording the species and sizes of recruits, maintaining a depth approximately equidistant between the water surface and seafloor. Once the outer perimeter of the kelp forest was again reached, the diver would descend once more and record recruits along the bottom while deploying a meter tape to measure the distance traversed to the inner edge of the kelp forest. This distance was then used to determine the mean number of recruit fishes per unit volume $\left(\sim 20 \mathrm{~m}^{3}\right)$ per stratum for each transect.

For surveys of older life stages of fishes, juvenile $(\sim 1$ yr or older) and adult fishes were combined into 1 category (hereafter referred to as older fishes) because our observations and prior studies did not reveal substantive differences in habitat use between these 2 life stages (e.g. Larson \& DeMartini 1984). Surveys to explore the effects of fragmentation on older fishes were performed in July and August 2005 and 2006, and July and August 2007 at Quarry. The dimensions of transects for these surveys were $2 \mathrm{~m}$ high $\times 2 \mathrm{~m}$ wide $\times \sim 20 \mathrm{~m}$ long $\left(80 \mathrm{~m}^{3}\right)$ to encompass the large size and mobility of older fishes, and fishes were enumerated by species with visual estimates of their size (TL, cm). No transects were established in the kelp canopy because older fishes are not as strongly associated with this stratum as are young recruits (e.g. Anderson 1994).

Kelp patch size and recruitment: experimental design. To determine the relationship between recruitment of kelp-associated fishes and patches of kelp at smaller spatial scales, we experimentally manipulated kelp in isolated stands. In July 2006, individual kelp were translocated from Patch Reef (Fig. 1a) to a featureless sand bottom adjacent to the reef and secured with rope and earth anchors. Patches of kelp were constructed with increasing area but standardized to the density of kelp (individuals spaced equally from one another at a distance of $1 \mathrm{~m}$ and treatments were separated from one another by a distance of $10 \mathrm{~m}$ in order to prevent the movement of post-settlement recruit fishes). Each patch received 1, 2, $3,4,6,9,12$, or 16 individual kelp, constituting total patch areas of $0.06,0.25,0.43,1.0,1.7,4.0,6.0$, and $9.0 \mathrm{~m}^{2}$, respectively. We established 4 plots for each patch area of $0.06,0.25$, and $0.43 \mathrm{~m}^{2}, 3$ plots for patch areas of 1.0 and $1.7 \mathrm{~m}^{2}$, and 1 plot for patch areas of $4.0,6.0$, and $9.0 \mathrm{~m}^{2}$ (Table 1b). A greater number of smaller patches were constructed because of expected higher variability in recruitment with decreasing patch size.

After construction of patches, recruitment of fishes was monitored after 2 and 4 wk. Teams of 2 (smaller patches) or 4 observers (large patches $\geq 6$ individual kelp) counted recruits to reduce potential doublecounting and to ensure that all recruits were included. Within each patch, each individual kelp was searched intensively for all recruits associated with giant kelp, beginning at the kelp canopy and descending to the substratum. On larger patches, censuses from each observer were summed to obtain an overall abundance of recruits in each patch.

This same experiment was repeated in June 2007 at a different site (Big Fisherman Cove, Fig. 2a). Three plots each were constructed for patch areas of 0.06 , 0.25 , and $0.43 \mathrm{~m}^{2}, 2$ for areas of 1.0 and $1.7 \mathrm{~m}^{2}$, and 1 for a patch area of $4.0 \mathrm{~m}^{2}$. We did not construct plots $>4.0 \mathrm{~m}^{2}$ because of limited space on sandy bottom and a focus on smaller patch areas because of variability in recruitment observed in small patches the previous year. All plots $\geq 0.43 \mathrm{~m}^{2}$ in patch area were censused by 
multiple observers to reduce the probability of doublecounting, and recruitment was monitored after 2, 4 and $6 \mathrm{wk}$.

Analyses. Habitat fragmentation: For a given survey at a site within a year, the numerical densities of both recruit and older fishes per fragment were calculated by summing counts of fishes on a transect across depth strata and standardizing the density per unit volume $\left(100 \mathrm{~m}^{3}\right)$. The densities obtained for each transect were then averaged to obtain a mean density of fish per fragment. The mean densities for each fragment at a site were then averaged across monthly surveys to determine an overall mean density for each fragment size and year. The overall mean densities for each year $(2005,2006)$ were then averaged to obtain the mean density of fish for each fragment at a site observed over the course of the experiment. The same procedure was used to determine biomass density; standard length measurements of older fishes were converted to weight using length-weight relationships (Cailliet et al. 2000, T. Anderson unpublished data), from which biomass density per unit volume was determined.

We focused on abundance with respect to habitat fragmentation because the densities of fishes determined in the 3 strata (kelp canopy, midwater, bottom) were integrated across the water column. To obtain the numerical and biomass abundances of fishes, numerical and biomass densities were extrapolated by integrating the density of fishes (ind. $100 \mathrm{~m}^{-3}$ ) in each depth stratum proportionally to the extent of the water column to determine the density per unit area of reef (ind. $100 \mathrm{~m}^{-2}$ ), taking into account the larger volume represented by midwater transects. This area was then extrapolated to the size of a kelp fragment to achieve an overall abundance. The numerical and biomass abundances of fishes per fragment among sites were then compared to fragment size using linear and non-linear regression.

The relationship between the abundance of fishes and kelp fragment size was described by the model (linear, exponential, or asymptotic) with the best fit as determined by the highest coefficient of determination $\left(\mathrm{r}^{2}\right)$. The 3 models were also compared using Akaike's Information Criterion (AIC; Motulsky \& Christopoulos 2003). For all species of recruit and older fishes that exhibited significant non-linear relationships between their numerical or biomass abundance and fragment size, linear regression as a conservative standard of habitat loss was also performed for comparison with the fit of non-linear models. The abundances of recruit and older fishes from single surveys at Quarry and 3 larger naturally occurring kelp forests in 2007 were summarized using the same methods as described above and analyzed using linear and non-linear regression.

Statistical analyses were conducted only for those species with sufficient densities for meaningful com- parisons, although analyses of all species combined contained all fishes surveyed (Table 2). Older fishes included for analysis by species, in order of decreasing density, were Chromis punctipinnis, Paralabrax clathratus, Brachyistius frenatus, Hypsypops rubicundus, Girella nigricans, Halichoeres semicinctus, Semicossyphus pulcher, and Oxyjulis californica. Recruit fishes included for analysis were C. punctipinnis, P. clathratus, $B$. frenatus, and $O$. californica.

To determine differences in the density of kelp among sizes of fragments and sites, counts of kelp fronds among transects in a fragment were averaged to assess the density of fronds (no. $40 \mathrm{~m}^{-2}$ ) per fragment at each site. The densities of kelp fronds were then averaged between years $(2005,2006)$ and a 1 -way blocked analysis of variance (ANOVA) was used to determine whether the mean density of fronds differed significantly among fragments and sites. Data were inspected for assumptions of normality and homogeneity of variances and log-transformed as necessary to meet these assumptions.

Patch size and recruitment: In the first experiment to examine kelp patch size and recruitment of fishes, only

Table 2. Fish species (older juveniles/adults and recruits) recorded during kelp forest surveys (2005 to 2007), in decreasing order of abundance; ${ }^{*}$ sufficiently abundant for statistical analysis. All species recorded were incorporated into analyses of 'all species combined'

\begin{tabular}{|ll}
\hline Species & Common name \\
\hline Older juvenile and adult fishes & \\
Chromis punctipinnis & Blacksmith* \\
Paralabrax clathratus & Kelp bass* \\
Brachyistius frenatus & Kelp perch* \\
Hypsypops rubicundus & Garibaldi* \\
Girella nigricans & Opaleye* \\
Halichoeres semicinctus & Rock wrasse* \\
Semicossyphus pulcher & California sheephead* \\
Oxyjulis californica & Señorita \\
Medialuna californiensis & Halfmoon \\
Embiotoca jacksoni & Black perch \\
Xenistius californiensis & Salema \\
Heterostichus rostratus & Giant kelpfish \\
Rhacochilus toxotes & Rubberlip seaperch \\
Hermosilla azurea & Zebraperch \\
Anisotremus davidsonii & Sargo \\
Paralabrax nebulifer & Barred sand bass \\
Rhacochilus vacca & Pile perch \\
Hypsurus caryi & Rainbow seaperch \\
Recruit fishes & \\
Chromis punctipinnis & Blacksmith* \\
Paralabrax clathratus & Kelp bass* \\
Brachyistius frenatus & Kelp perch* \\
Oxyjulis californica & Señorita* \\
Heterostichus rotratus & Giant kelpfish \\
Embiotoca jacksoni & Black perch \\
Halichoeres semicinctus & Rock wrasse \\
Cymatogaster aggregata & Shiner perch \\
& \\
\hline
\end{tabular}


the second survey ( $1 \mathrm{mo}$ ) was employed because no recruits were observed during the first survey at $2 \mathrm{wk}$. For the second experiment, observations of recruits were averaged over 3 biweekly surveys. For both experiments, the relationship between patch size and the density of recruits was examined with linear regression and a negative exponential regression function. Linear regression was performed on log-transformed data to meet the assumption of homogeneity of variances.

\section{RESULTS}

\section{Effects of habitat fragmentation on kelp forest fishes}

Because kelp density did not differ among sites or fragments throughout our experiment $(\mathrm{p}=0.82$ and 0.20 for fragment and site, respectively) we examined the observed relationships between fish numerical or biomass abundance and fragment size. The relationships between the numerical abundance of older fishes and kelp fragment size were described by different positive regression functions among species (Table 3). We selected the best fit models using the highest coefficient of determination $\left(\mathrm{r}^{2}\right)$. Model selection using AIC evidence ratios did not provide clear evidence with our data to favor any one model over another for all species and life stages (see Tables $3 \& 4$ ).

For all species combined, there was a positive linear function between numerical abundance and fragment size (Fig. 3a). Of 3 common kelp forest fishes in southern California, Chromis punctipinnis exhibited a linear function with numerical abundance (Fig. 3c), while Oxyjulis californica and Paralabrax clathratus were best described by exponential (Fig. 3e) and asymptotic (Fig. 3g) functions, respectively. The biomass abundance of older fishes (Table 3) revealed positive linear relationships with fragment size for all species combined (Fig. 3b) and all species analyzed independently, except for O. californica (Fig. 3f) and Halichoeres semicinctus, which exhibited exponential and asymptotic relationships, respectively. For recruit fishes (Table 3), numerical abundance was linearly related to kelp fragment size for all species combined, C. punctipinnis, and O. californica (Fig. 4a-c). P. clathratus (Fig. 4d) and Brachyistius frenatus were best described by asymptotic relationships.

Interestingly, the numerical abundances of fishes in 2007 at Quarry (the only remaining intact site) and 3 much larger natural kelp forests revealed relationships

Table 3. Relationships between numerical or biomass abundance and kelp fragment size for older fishes and recruits in 2005 and 2006 combined. Best-fit relationships between abundance of fishes and kelp fragment size as determined by the highest $\mathrm{r}^{2}$ values. 'Percentage more variation' is the amount of additional variation explained by the non-linear model than by a linear model. The Akaike Information Criterion (AIC) evidence ratio is a multiplier indicating the 'better' fit of a linear model vs. the non-linear models. 'All species combined' includes all older fishes and recruit fishes recorded on surveys (see Table 2). Full species names are listed in Table 2

\begin{tabular}{|c|c|c|c|c|c|c|}
\hline & Species & $\begin{array}{c}\text { Numerical or } \\
\mathrm{r}^{2}\end{array}$ & $\begin{array}{l}\text { nass abundance } \\
\qquad \mathrm{p}\end{array}$ & $\begin{array}{l}\text { Regression } \\
\text { function }\end{array}$ & $\begin{array}{c}\% \text { more } \\
\text { variation }\end{array}$ & $\begin{array}{l}\text { AIC evidence } \\
\text { ratio }\end{array}$ \\
\hline Older fishes & All species combined & 0.95 & $<0.001$ & Linear & - & 1.15 \\
\hline Numerical & C. punctipinnis & 0.79 & $<0.001$ & Linear & - & 1.11 \\
\hline \multirow[t]{7}{*}{ abundance } & P. clathratus & 0.87 & $<0.001$ & Asymptotic & 4 & 1.12 \\
\hline & B. frenatus & 0.76 & $<0.001$ & Exponential & 1 & 1.27 \\
\hline & H. rubicundus & 0.87 & $<0.001$ & Linear & - & 1.11 \\
\hline & G. nigricans & 0.68 & $<0.001$ & Asymptotic & 16 & 1.12 \\
\hline & H. semicinctus & 0.84 & $<0.001$ & Asymptotic & 7 & 1.11 \\
\hline & S. pulcher & 0.73 & $<0.001$ & Exponential & 6 & 1.30 \\
\hline & O. californica & 0.66 & 0.002 & Exponential & 13 & 1.24 \\
\hline \multirow{9}{*}{$\begin{array}{l}\text { Biomass } \\
\text { abundance }\end{array}$} & All species combined & 0.85 & $<0.001$ & Linear & - & 1.11 \\
\hline & C. punctipinnis & 0.62 & 0.002 & Linear & - & 1.11 \\
\hline & P. clathratus & 0.89 & $<0.001$ & Linear & - & 1.20 \\
\hline & B. frenatus & 0.87 & 0.001 & Linear & - & 1.11 \\
\hline & H. rubicundus & 0.90 & $<0.001$ & Linear & - & 1.49 \\
\hline & G. nigricans & 0.41 & 0.005 & Linear & - & 1.26 \\
\hline & H. semicinctus & 0.85 & $<0.001$ & Asymptotic & 2 & 7.50 \\
\hline & S. pulcher & 0.61 & $<0.002$ & Linear & - & 1.16 \\
\hline & O. californica & 0.69 & 0.003 & Exponential & 11 & 1.25 \\
\hline Recruit fishes & All species combined & 0.84 & $<0.001$ & Linear & - & 1.12 \\
\hline Numerical & C. punctipinnis & 0.42 & 0.03 & Linear & - & 1.11 \\
\hline \multirow{3}{*}{ abundance } & P. clathratus & 0.52 & 0.007 & Asymptotic & 8 & 1.26 \\
\hline & B. frenatus & 0.45 & $<0.002$ & Asymptotic & 14 & 1.43 \\
\hline & O. californica & 0.42 & 0.03 & Linear & - & 1.22 \\
\hline
\end{tabular}


(Table 4) that often differed from those observed at our experimental sites in 2005/2006 (Table 3). For example, the numerical abundances of all species combined, Chromis punctipinnis, and Hypsypops rubicundus in 2007 showed exponential, linear, and asymptotic

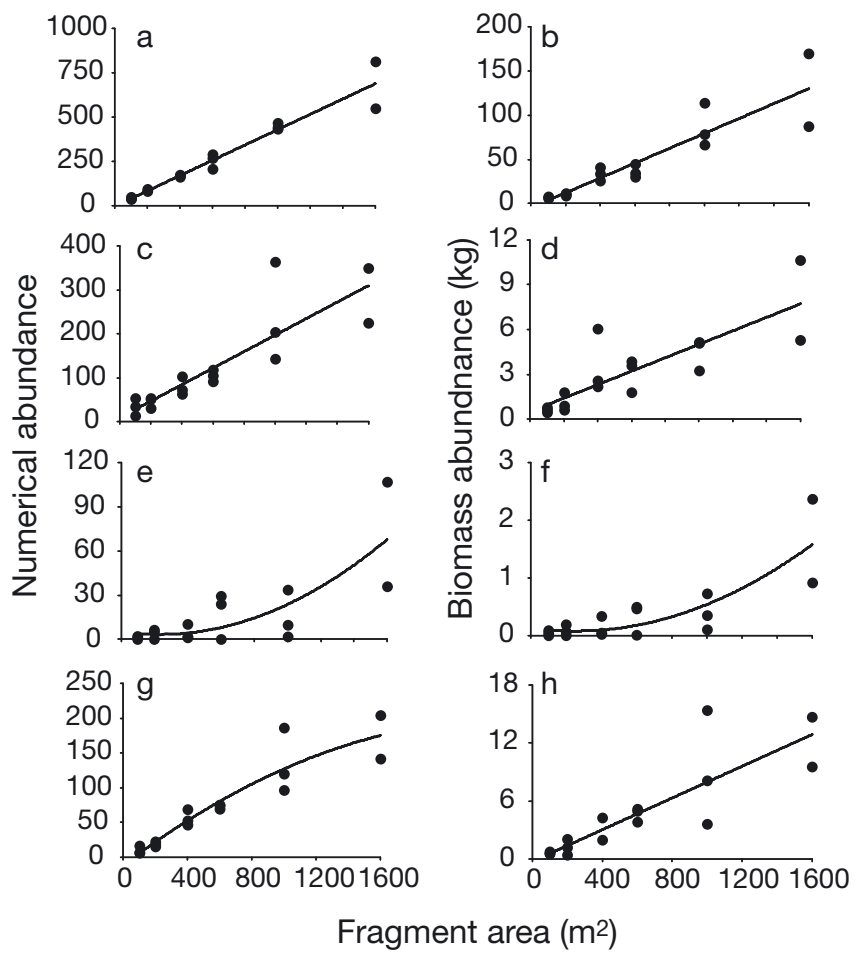

Fig. 3. Relationships between the numerical (left column) and biomass (right column) abundance of older fishes and fragment size for $(\mathrm{a}, \mathrm{b})$ all species combined, $(\mathrm{c}, \mathrm{d})$ Chromis punctipinnis, $(\mathrm{e}, \mathrm{f})$ Oxyjulis californica, and $(\mathrm{g}, \mathrm{h})$ Paralabrax clathratus in 2005 to 2006

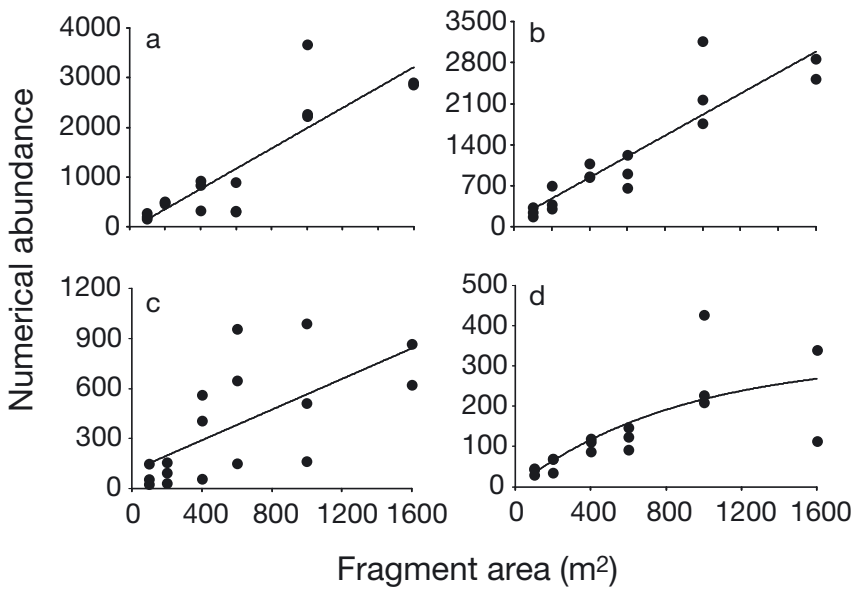

Fig. 4. Relationships between the numerical abundance of recruit fishes and fragment size for (a) all species combined, (b) Chromis punctipinnis, (c) Oxyjulis californica, and (d) Paralabrax clathratus in 2005 to 2006 relationships with the size of kelp fragments and forests (Fig. $5 \mathrm{a}-\mathrm{c}$ ). By contrast, these species exhibited either linear or asymptotic functions of these relationships in 2005/2006. Including larger naturally occurring kelp fragments in our analyses also changed the relationships between the biomass abundance of older fishes and the size of kelp fragments and forests. The biomass abundances of fishes observed in 2005/2006 were altered from mostly additive functions to either asymptotic or exponential relationships (Table 4). For recruit fishes, the numerical abundances of recruits surveyed in 2007 (Table 4) also revealed relationships that differed from those obtained in 2005/2006. The numerical abundances of all species combined and Oxyjulis californica were exponentially related to the size of kelp fragments and forests in 2007, but both showed linear relationships in abundance with fragment size in 2005/2006. C. punctipinnis showed additive relationships for both time periods. Paralabrax clathratus was not included in these analyses because recruitment was negligible in 2007 .
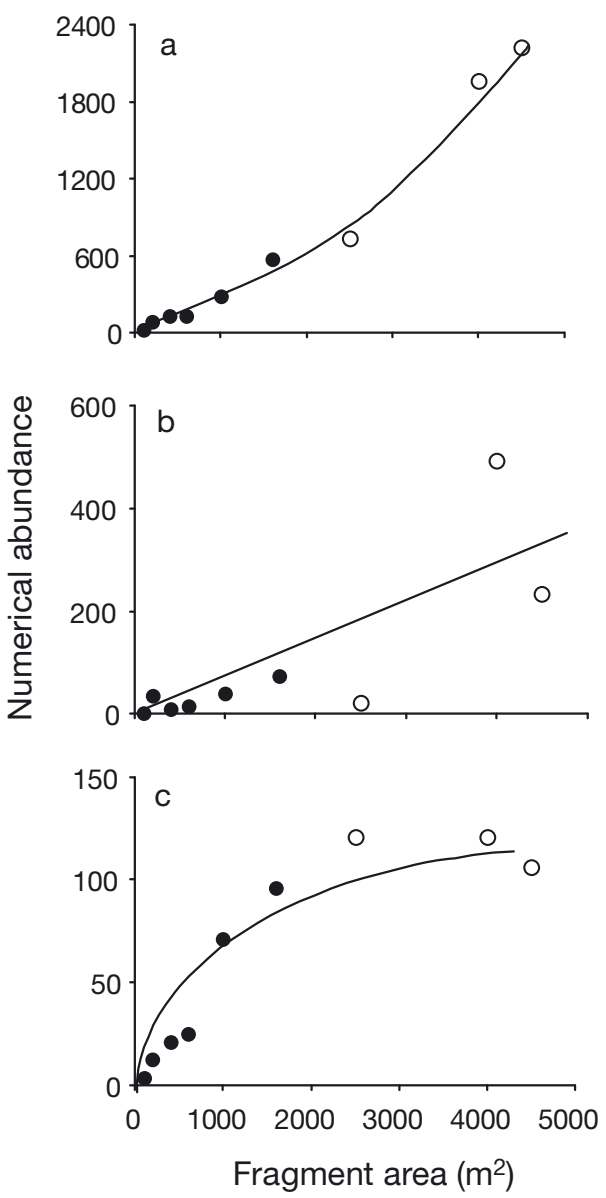

Fig. 5. Relationship between the numerical abundance of older fishes and kelp fragment or forest size for (a) all species combined, (b) Chromis punctipinnis, and (c) Hypsypops rubicundus in 2007. (•) data from experimental fragments at Quarry; (O) data from naturally occurring kelp forests 
Table 4. Relationships between numerical or biomass abundance and kelp fragment/forest size for recruits and older fishes in 2007. Regression functions describe the best-fit relationships as determined by $\mathrm{r}^{2}$ values. The meso-scale regression function shows the best-fit models from the meso-scale experiment in 2005 and 2006 combined. The Akaike Information Criterion (AIC) evidence ratio is a multiplier indicating the 'better' fit of a linear model vs. the non-linear models. 'All species combined' includes all older fishes or recruit fishes recorded on surveys (see Table 2). Full species names are listed in Table 2

\begin{tabular}{|c|c|c|c|c|c|c|}
\hline & Species & $\begin{array}{c}\text { Numerical ol } \\
\mathrm{r}^{2}\end{array}$ & $\begin{array}{l}\text { nass abundance } \\
\text { p }\end{array}$ & $\begin{array}{l}\text { Regression } \\
\text { function }\end{array}$ & $\begin{array}{l}\text { Meso-scale } \\
\text { regression }\end{array}$ & $\begin{array}{l}\text { AIC evidence } \\
\text { ratio }\end{array}$ \\
\hline Older fishes & All species combined & 0.96 & $<0.001$ & Exponential & Linear & 1.12 \\
\hline Numerical & P. clathratus & 0.95 & $<0.001$ & Exponential & Asymptotic & 1.13 \\
\hline \multirow[t]{4}{*}{ abundance } & H. semicinctus & 0.96 & $<0.001$ & Exponential & Asymptotic & 1.14 \\
\hline & C. punctipinnis & 0.66 & 0.01 & Linear & Linear & 1.12 \\
\hline & H. rubicundus & 0.94 & $<0.001$ & Asymptotic & Linear & 1.11 \\
\hline & B. frenatus & 0.71 & 0.004 & Linear & Linear & 1.13 \\
\hline \multirow{6}{*}{$\begin{array}{l}\text { Biomass } \\
\text { abundance }\end{array}$} & All species combined & 0.96 & 0.05 & Asymptotic & Linear & 1.12 \\
\hline & P. clathratus & 0.94 & 0.002 & Exponential & Linear & 1.11 \\
\hline & H. semicinctus & 0.98 & $<0.001$ & Exponential & Asymptotic & 1.13 \\
\hline & C. punctipinnis & 0.63 & $<0.001$ & Exponential & Linear & 1.14 \\
\hline & H. rubicundus & 0.90 & $<0.001$ & Asymptotic & Linear & 1.16 \\
\hline & B. frenatus & 0.74 & 0.02 & Asymptotic & Linear & 1.11 \\
\hline Recruit fishes & All species combined & 0.91 & 0.008 & Exponential & Linear & 1.40 \\
\hline Numerical & C. punctipinnis & 0.50 & 0.02 & Linear & Linear & 1.17 \\
\hline abundance & O. californica & 0.97 & $<0.001$ & Exponential & Linear & 1.11 \\
\hline
\end{tabular}

\section{Relationships between kelp patch size and recruitment}

In 2006, Paralabrax clathratus was the only species with substantial recruitment to the experimental array, whereas in 2007, recruits consisted mostly of Oxyjulis californica. The density of recruit $P$. clathratus was unrelated to kelp patch size $(p=0.33)$ in 2006. Both high densities of recruits and high variability in recruitment (Fig. 6a) were observed for smaller patches $\leq 2 \mathrm{~m}^{2}$. Similar to $P$. clathratus recruitment in 2006, the density of O. californica in 2007 was unrelated to kelp patch size $(\mathrm{p}=0.51)$, and recruitment was high and variable at smaller patch sizes (Fig. 6b).

\section{DISCUSSION}

Understanding habitat fragmentation and its effects on marine organisms is becoming increasingly important due to the frequency, magnitude, and sometimes permanency of the many natural and anthropogenic sources of disturbance. Relative to terrestrial ecosystems, however, few studies have been conducted on habitat fragmentation in the marine environment. Of these, seagrass beds have been a primary focus, with the effects of fragmentation examined observationally at larger spatial scales (Hovel \& Lipcius 2002) or experimentally through manipulation of habitat or organisms at much smaller spatial scales (Eggleston et al. 1998, Healey \& Hovel 2004). Few studies have attempted to decouple the effects of habitat loss from fragmentation (but see Caley et al. 2001), making the results difficult to interpret (Fahrig 2003).

In our study of habitat fragmentation and its effects on the recruitment and abundance of kelp forest

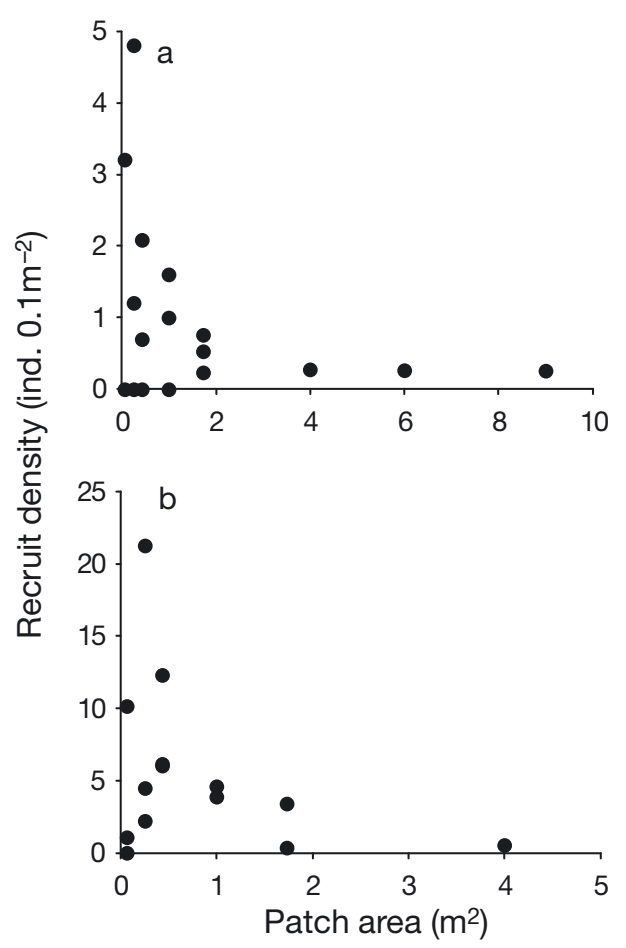

Fig. 6. Paralabrax clathratus and Oxyjulis californica. Relationship between the density of recruit fishes and kelp patch size for (a) P. clathratus in 2006 and (b) O. californica in 2007 
fishes, we used meso-scale (100s of meters) experimental manipulations to investigate whether habitat fragmentation influences the density and abundance of recruit and older fishes within and among giant kelp forests. Our approach was to specifically evaluate the relative importance of habitat fragmentation versus habitat loss by determining the shape of the regression functions in the numerical and biomass abundances of fishes across a gradient of kelp fragment size. We selected the best fit models using the highest coefficient of determination $\left(\mathrm{r}^{2}\right)$ because comparisons made using AIC did not improve our ability to select the best model. Overall, we often observed linear relationships between the numerical or biomass abundance and kelp fragment size for many species, and for those functions that were non-linear, there was little added variation explained in comparison to a linear model.

The additive, linear functions exhibited in many species and in all instances for all species combined for numerical abundance and biomass and across life stages suggest that kelp forest fishes are much more strongly affected by the loss of habitat than by its fragmentation, consistent with some studies in other marine (Caley et al. 2001) and terrestrial ecosystems (Fahrig 2003). The prevalence of linear functions observed here is likely a consequence of similar but variable densities of fishes across a gradient in kelp fragment size. In this temperate marine ecosystem, the mobility of many older juvenile and adult fishes (Lowe \& Bray 2006), and the high potential for dispersal of pre-settlement larvae (Caley et al. 1996, Carr \& Syms 2006) may render habitat fragmentation inconsequential in affecting the density of most recruit or older fishes within and among kelp forests at this spatial scale. The habitat associations of recruit fishes in particular occur at small spatial scales and are largely influenced by structural habitat complexity and are likely to be much less affected by the areal extent of the habitat itself. One consequence of habitat fragmentation that we did not address is the distance between or isolation of fragments. Because of the much greater mobility and dispersal potential of these fishes, however, we do not expect the degree of isolation to be important relative to habitat fragmentation area and loss in kelp forests. Many older fishes are highly mobile and are more loosely associated with their habitat and therefore may travel among fragments of kelp forests with little consequence. Similarly, recruits of kelp-associated fishes are capable of settling from the plankton to patches of kelp regardless of their isolation from one another.

Despite the experimental fragmentation of kelp forests, incorporating even larger natural kelp forests suggests that larger areas of discrete kelp forests, separated by less suitable habitat, may be an important issue in describing the relationship between fish abundance and habitat area. When including much larger kelp forests in surveys of the density and abundance of fishes in 2007, the relationships between numerical abundance or total biomass and kelp fragment size were altered from linear to non-linear functions for several species and for all species combined. Recruit fishes also exhibited similar changes, exhibiting exponential functions for all species combined and for Oxyjulis californica that were described by linear functions from the meso-scale experiment. Although the greater amount of variation explained by these non-linear functions was generally $<15 \%$ versus a linear model, non-linear relationships were observed with a much greater frequency. As kelp forests become much larger and are defined by discrete boundaries of rocky reef habitat, fishes may be more likely to restrict their movements within kelp habitat at the scale of these kelp forests. These results must be interpreted with caution, however, because we were able to survey only 3 large kelp forests, and the data from 2 of these forests were important drivers of the non-linear relationships.

By contrast, the sizes of very small patches of giant kelp appear to be unrelated to recruitment of kelpassociated fishes. Both Paralabrax clathratus and Oxyjulis californica certainly are capable of settling to small patches of habitat consisting of an individual kelp. Although there is high variation in recruitment among smaller patches, the density of recruits does not increase with patch area. Variation in recruitment of kelp-associated fishes appears to be much more strongly linked to structural habitat complexity in the density of fronds or individuals (Ebeling \& Laur 1985, Carr 1994), blade biomass (Carr 1994), and the percentage cover of the kelp canopy (Anderson 1994). However, these results do not address the persistence of recruits in patches of different size. For example, if predator-induced mortality (Anderson 2001, Johnson 2006) is relatively higher in small than large patches because there is less physical refuge, the frequency distribution of sizes of kelp patches may be important in determining the magnitude of recruitment at a location. If so, fragmentation at small spatial scales may alter recruitment success more than these results suggest. Nonetheless, habitat loss appears to play a much larger role in recruitment success with kelp patch size than does the degree of fragmentation of kelp forests.

In summary, the patterns of density and abundance observed in this study are somewhat similar to previous research that describes the effects of habitat fragmentation in marine and terrestrial ecosystems. The effects of fragmentation can vary in strength and affect species differentially (Eggleston et al. 1998) and are 
also dependent on the scale at which studies are conducted (Fahrig 2003). In this case, however, habitat loss is more likely to impact kelp forest fishes within kelp forests than fragmentation is, although fragmentation may assume a greater role in its effects among kelp forests at larger spatial scales.

The relationships described here may provide useful information to resource managers responsible for the conservation of nearshore habitats. The effectiveness of a marine protected area (MPA) is often assumed to be a reflection of its size because of the possibility of preserving a continuous stretch of productive marine habitat and its associated fauna (Claudet et al. 2008). This type of reserve strategy, however, may be more effective for sedentary species or species with low dispersal distances (such as surfperches, family Embiotocidae) and less appropriate for retaining species that are more mobile and have greater larval dispersal (Botsford et al. 2001, Kaplan et al. 2006). Recent modeling studies have suggested that the percentage of coastline incorporated into a reserve and the connectivity among reserves is a more critical component for MPA effectiveness than reserve size alone (Kaplan et al. 2006, Moffitt et al. 2009). Our results suggest that the densities of kelp forest fishes are more closely related to the presence of habitat than to habitat area. However, when considering the observational results we obtained when surveying well-defined large kelp forests, it is possible that fish-habitat relationships have the potential to change depending on spatial scale. In our study, data from large kelp forests defined by suitable rocky habitat suggests that the loss of kelp habitat may be increasingly important. A plausible mechanism for the higher abundances of fishes in these forests is that individuals may spend much more time over rocky reef habitat as opposed to moving over considerable distances of featureless sand bottom to other suitable habitat.

When implementing marine protected areas as a management tool (Greenville \& Macaulay 2007, Claudet et al. 2008) to replenish coastal reef-associated fish populations in temperate regions, we suggest that one should consider the area of hard substratum (and thus kelp habitat) more so than its configuration (e.g. the fraction of rocky reef coastline within a proposed MPA), the prevalence and variability in the cover of kelp from disturbance as it relates to habitat loss and not fragmentation, and the distribution of larger kelp forests and the distances of unsuitable habitat between them with the goal of increasing residence times of economically important species within MPAs. Clearly, future research should address the causes and consequences of habitat loss and fragmentation of coastal marine habitats at scales appropriate for ecosystembased management.
Acknowledgements. We thank K. O'Connor and T. Goodman for assistance in all field experiments related to this project, and D. Cie, A. Davenport, C. Faist, M. Edwards, S. Fejtek, E. Floyd, C. Galst, P. Kutchner, L. Lewis, and P. Matson for their help with experimental manipulations. This research was conducted in partial fulfillment of a Master's degree by A.A.D., and we thank M. Edwards for statistical advice and for reviewing the manuscript. We also thank the staff of the Wrigley Marine Science Center for their assistance and logistical support. This research was funded by grants from NOAA's National Undersea Research Program, West Coast Polar Region Center (UAF[CA]-03-02), the National Institute for Undersea Science and Technology (05-07-006) and the National Science Foundation (OCE-0331895) to T.W.A. and by the San Diego State University Department of Biology Ecology Program to A.A.D. We also thank the anonymous reviewers for their constructive criticism and comments which improved the manuscript. This is Contribution Nr. 247 of the Wrigley Institute for Environmental Studies.

\section{LITERATURE CITED}

Anderson TW (1994) Role of macroalgal structure in the distribution and abundance of a temperate reef fish. Mar Ecol Prog Ser 113:279-290

Anderson TW (2001) Predator responses, prey refuge, and density-dependent mortality of a marine fish. Ecology 82: 245-257

Andrén H (1994) Effects of habitat fragmentation on birds and mammals in landscapes with different proportions of suitable habitat: a review. Oikos 71:355-366

Bell SS, McCoy ED, Mushinsky HR (eds) (1991) Habitat structure: the physical arrangement of objects in space. Chapman \& Hall, London

Bodkin JL (1986) Fish assemblages in Macrocystis and Nereocystis kelp forests off central California. Fish Bull 84: 799-808

> Bodkin JL (1988) Effects of kelp forest removal on associated fish assemblages in central California. J Exp Mar Biol Ecol 117:227-238

Botsford LW, Hastings A, Gaines SD (2001) Dependence of sustainability of configuration and larval dispersal distance. Ecol Lett 4:144-150

Bowden DA, Rowden AA, Martin J (2001) Effect of patch size and in-patch location on the infaunal macroinvertebrate assemblages of Zostera marina seagrass beds. J Exp Mar Biol Ecol 259:133-154

Cailliet GM, Burton EJ, Cope JM, Kerr LA (2000) Biological characteristics of nearshore fishes of California: a review of existing knowledge and proposed additional studies for the Pacific Ocean interjurisdictional fisheries management plan coordination and development. Available at www.dfg.ca.gov/marine/lifehistories/index.asp

Caley MJ, Carr MH, Hixon MA, Hughes TP, Jones GP, Menge BA (1996) Recruitment and the local dynamics of open marine populations. Annu Rev Ecol Syst 27:477-500

Caley MJ, Buckley KA, Jones GP (2001) Separating ecological effects of habitat fragmentation, degradation, and habitat loss on coral commensals. Ecology 82:3435-3448

Carr MH (1989) Effects of macroalgal assemblages on the recruitment of temperate zone reef fishes. J Exp Mar Biol Ecol 126:59-76

> Carr MH (1991) Habitat selection and recruitment of an assemblage of temperate zone reef fishes. J Exp Mar Biol Ecol 146:113-137

Carr MH (1994) Effects of macroalgal dynamics on recruit- 
ment of temperate reef zone fish. Ecology 75:1320-1333

Carr MH, Syms C (2006) Recruitment. In: Allen LG, Pondella DJ, Horn $\mathrm{MH}$ (eds) The ecology of marine fishes: California and adjacent waters. University of California Press, Berkley \& Los Angeles, CA, p 411-427

Choat JH, Ayling AM (1987) The relationship between habitat structure and fish faunas on New Zealand reefs. J Exp Mar Biol Ecol 110:257-284

Claudet J, Osenberg CW, Benedetti-Cecchi L, Domenici P and others (2008) Marine reserves: size and age do matter. Ecol Lett 11:481-489

Conner RN, Rudolph DC (1991) Forest habitat loss, fragmentation, and red-cockaded woodpecker populations. Wilson Bull 103:446-457

Cowen RK, Agegian CR, Forester MS (1982) The maintenance of community structure in a central California giant kelp forest. J Exp Mar Biol Ecol 64:189-201

Crist TO, Ahern RG (1999) Effects of habitat patch size and temperature on the distribution and abundance of ground beetles in an old field. Environ Entomol 28:681-689

- Dayton PK (1985) Ecology of kelp communities. Annu Rev Ecol Syst 16:215-245

> Dayton PK, Tegner MJ, Parnell PE, Edwards PB (1992) Temporal and spatial patterns of disturbance and recovery in a kelp forest community. Ecol Monogr 62:421-445

DeMartini EE, Roberts DA (1990) Effects of giant kelp (Macrocystis) on the density and abundance of fishes in a cobblebottom kelp forest. Bull Mar Sci 46:287-300

> Devinny JS, Volse LA (1978) Effects of sediments on the development of Macrocystis pyrifera gametophytes. Mar Biol 48:343-348

Ebeling AW, Hixon MA (1991) Tropical and temperate reef fishes: comparison of community structures. In: Sale PF (ed) The ecology of fishes on coral reefs. Academic Press, San Diego, CA, p 509-563

Ebeling AW, Laur DR (1985) The influence of plant cover on surfperch abundance at an offshore temperate reef. Environ Biol Fishes 12:169-179

- Ebeling AW, Laur DR, Rowley RJ (1985) Severe storm disturbances and reversal of community structure in a southern California kelp forest. Mar Biol 84:287-294

Edwards MS, Estes JA (2006) Catastrophe, recovery and range limitation in NE Pacific kelp forests: a large-scale perspective. Mar Ecol Prog Ser 320:79-87

Edwards MS, Hernandez-Carmona G (2005) Delayed recovery of giant kelp near its southern range limit in the north Pacific following El Niño. Mar Biol 147:273-279

Eggleston DB, Etherington LL, Elis WE (1998) Organism response to habitat patchiness: species and habitatdependent recruitment of decapod crustaceans. J Exp Mar Biol Ecol 223:111-132

Fahrig L (2003) Effects of habitat fragmentation on biodiversity. Annu Rev Ecol Syst 34:487-515

Fernandez TV, Milazzo M, Badalamenti F, D'Anna G (2005) Comparison of the fish assemblages associated with Posidonia oceanica after the partial loss and consequent fragmentation of the meadow. Estuar Coast Shelf Sci 65: 645-653

Foster MS, Schiel DR (1985) The ecology of giant kelp forests in California: a community profile. Biol Rep US Fish Wildl Serv 85:1-152

Greenville J, Macaulay TG (2007) Untangling the benefits of protected areas in fisheries. Mar Resour Econ 22:267-285

> Healey D, Hovel KA (2004) Seagrass bed patchiness: effects on epifaunal communities in San Diego Bay, USA. J Exp Mar Biol Ecol 313:155-174

Hirst JA, Attrill MJ (2008) Small is beautiful: an inverted view

Editorial responsibility: Nicholas Tolimieri,

Seattle, Washington, USA of habitat fragmentation in seagrass beds. Estuar Coast Shelf Sci 78:811-818

Hokit DG, Branch LC (2003) Habitat patch size affects demographics of the Florida scrub lizard. J Herpetol 37:257-265

Holbrook JS, Carr MH, Schmitt RJ, Coyer JA (1990) Effects of giant kelp on local abundance of reef fishes: the importance of ontogenetic resource requirements. Bull Mar Sci 47:104-114

Hovel KA, Lipcius RN (2001) Habitat fragmentation in a seagrass landscape: patch size and complexity control blue crab survival. Ecology 82:1814-1829

- Hovel KA, Lipcius RN (2002) Effects of seagrass habitat fragmentation on juvenile blue crab survival and abundance. J Exp Mar Biol Ecol 271:75-98

Jackson GA (1997) Currents in the high drag environment of a coastal kelp stand off California. Cont Shelf Res 17: 1913-1928

Jelbart JE, Ross PM, Connolly RM (2006) Edge effects and patch size in seagrass landscapes: an experimental test using fish. Mar Ecol Prog Ser 319:93-102

Johnson DW (2006) Predation, habitat complexity, and variation in density-dependent mortality of temperate reef fishes. Ecology 87:1179-1188

Johnson MW, Heck KL (2006) Effects of habitat fragmentation per se on decapods and fishes inhabiting seagrass meadows in the northern Gulf of Mexico. Mar Ecol Prog Ser 306:233-246

Kaplan DM, Botsford LW, Jorgensen S (2006) Dispersal per recruit: an efficient method for assessing sustainability in marine reserve networks. Ecol Appl 16:2248-2263

Larson RJ, DeMartini EE (1984) Abundance and vertical distribution of fishes in a cobble-bottom kelp forest off San Onofre, California. Fish Bull 82:37-53

Lowe CG, Bray RN (2006) Movement and activity patterns. In: Allen LG, Pondella DJ, Horn MH (eds) The ecology of marine fishes: California and adjacent waters. University of California Press, Berkley \& Los Angeles, CA, p 524-553

> Moffitt EA, Botsford LW, Kaplan DM, O'Farrel MR (2009) Marine reserve networks for species that move within a home range. Ecol Appl 19:1835-1847

$>$ Moreno CA, Jara HF (1984) Ecological studies on fish fauna associated with Macrocystis pyrifera belts in the south of Fueguian Islands, Chile. Mar Ecol Prog Ser 15:99-107

Motulsky H, Christopoulos A (2003) Fitting models to biological data using linear and nonlinear regression: a practical guide to curve fitting. GraphPad Software Inc., San Diego, CA

O'Connor KC, Anderson TW (2010) Consequences of habitat disturbance and recovery to the recruitment and abundance of kelp forest fishes. J Exp Mar Biol Ecol 386:1-10

Springer AM, Estes JA, Vliet GB, Williams TM, Doak DF, Danner EM, Forney KA, Pfister B (2003) Sequential megafaunal collapse in the North Pacific Ocean: an ongoing legacy of industrial whaling? Proc Natl Acad Sci USA 100:12223-12228

Stephens JS, Larson RJ, Pondella DJ (2006) Rocky reefs and kelp beds. In: Allen LG, Pondella DJ, Horn MH (eds) The ecology of marine fishes: California and adjacent waters. University of California Press, Berkley \& Los Angeles, CA, p 227-252

> Tegner MJ, Datyon PK, Edwards PB, Riser KL, Chadwick CB, Dean TA, Deysher L (1995) Effects of a large sewage spill on a kelp forest community: catastrophe or disturbance? Mar Environ Res 40:181-224

Wiegand T, Revilla E, Moloney KA (2005) Effects of habitat loss and fragmentation on population dynamics. Conserv Biol 19:108-121

Submitted: July 15, 2009; Accepted: August 23, 2010

Proofs received from author(s): October 1, 2010 